\title{
Zeta Potential Measurement in Bioactive Collagen
}

\author{
Ângela Leão Andrade ${ }^{\mathrm{a}, \mathrm{b} *}$, José Maria Fontes Ferreira ${ }^{\mathrm{b}}$, Rosana Zacarias Domingues ${ }^{\mathrm{a}}$ \\ ${ }^{a}$ Departamento de Química - ICEx - Universidade Federal de Minas Gerais \\ Av. Antônio Carlos, 6627, 31270-090, Belo Horizonte, Brazil \\ ${ }^{\mathrm{b}}$ Department of Ceramic and Glass Engineering, CICECO, \\ University of Aveiro, 3810-193, Aveiro, Portugal
}

Receive: October 29, 2003; Revised: May 20, 2004

\begin{abstract}
The focus of this work is to show the influence of surface charge on the bioactivity of modified collagen fiber surface. Because silica plays an important role on bone mineralization process, silica obtained by a sol-gel process was used as a surface modification agent. Zeta potential $(\xi)$ of silica-coated and non-coated samples was measured as a function of $\mathrm{pH}$. It was observed a shift in $\xi v s . \mathrm{pH}$. The isoelectric point for silica-coated collagen was 6.8, while that of non-treated sample it was near 10. Pure silica has isoelectric point near 2 , and the shift observed indicates that at least part of the silica was incorporated onto the surface during the treatment. The ability of samples exposed to biological simulated fluids (SBF) to form a hydroxyapatite layer has been used to recognize bioactive materials. The $\mathrm{pH}$ of these biological solutions is about 7.3. It means that treated samples acquire negative charge when in contact with the biological solution and attract ions like $\mathrm{Ca}^{2+}, \mathrm{HPO}_{4}^{2-}$, and $\mathrm{OH}$ to form HA coatings. Micrographs of chemically treated samples corroborate this assumption. For treated samples, the formation of a coating layer is clear after 5day immersion in SBF, while pure collagen remains practically unaltered. Fourier Transform Infrared Spectroscopic (FTIR) analyses confirmed that the coating layer has P-O vibration bands near $1060 \mathrm{~cm}^{-1}$ and $600 \mathrm{~cm}^{-1}$ characteristic of hydroxyapatite (HA).
\end{abstract}

Keywords: collagen, zeta potential, bioactivity

\section{Introduction}

A great number of materials have been used with success as bone substitutes. An important group has the ability to react with living tissues and promote a real interaction with them ${ }^{1,2}$. This interaction occurs by means of a hydroxyapatite (HA) layer formed inductively by the implanted material ${ }^{3,4}$. Due to experimental difficulties to accomplish in vivo assays ${ }^{5-9}$, bioactivity was evaluated in a acellular medium which simulates in vivo conditions. The first bioactive materials studied were glasses based on composition in the $\mathrm{SiO}_{2}-\mathrm{CaO}-\mathrm{P}_{2} \mathrm{O}_{5}-\mathrm{Na}_{2} \mathrm{O}$ system ${ }^{10}$.

Several theories have been proposed to explain the formation of this HA layer. In one of them, the basic unit responsible for this growth is the silanol group presents on the material surface ${ }^{11}$. Another hypothesis is that the formation of this layer happens when the material surface is negatively charged ${ }^{12,13}$. This negative surface could be able to attract $\mathrm{Ca}^{2+}$ cations and consequently $\mathrm{HPO}_{4}^{2-}$ and $\mathrm{OH}^{-}$anions dissolved in the SBF solution.

*e-mail: angelala01@ hotmail.com

Article presented at the II SBPMat, Rio de Janeiro - RJ, 26-29 de Outubro/ 2003
Zeta potential has traditionally been measured by electrophoresis, because all inorganic particles assume a charge when dispersed in water. By inserting electrodes into a suspension and applying a DC Voltage, the carged particles are attracted towards the anode (positive electrode). The velocity of the travelling particles depends on the particle surface charge (or zeta potential) and the voltage applied. Therefore if the velocity can be measured, zeta potential can be determined using the Henry or Van Smolukoski equations.

\section{Materials and methods}

\subsection{Samples and chemical treatment}

Type I collagen discs intended to be used as implant barriers (Asspress Cirúrgica Ltda.) were used as a substrate in this study. The samples were separate in two groups, chemically non-treated (control), and an experimental group whose samples were carefully placed into polyethylene vi- 
als with tetraethoxysilane (TEOS) at room temperature for $1 \mathrm{~h}$. After this time, TEOS was eliminated by filtration and the samples from both groups were washed with ethanol.

A silica glass control sample was prepared for zeta potential study. In this case, TEOS was added to an acidified ( $\mathrm{HCl}-\mathrm{pH} 1.7)$ aqueous solution, and next added with ethanol in a molar proportion of $\mathrm{H}_{2} \mathrm{O}$ :TEOS: $\mathrm{CH}_{3} \mathrm{CH}_{2} \mathrm{OH}$ of 4:1:4. The solution was magnetically stirred until gelation. The material was placed under a humidified atmosphere overnight, and next treated at $400{ }^{\circ} \mathrm{C}$ for $2 \mathrm{~h}$.

\subsection{SBF immersion test}

Individual fiber samples were immersed into a simulated body fluid (SBF) in polyethylene vials-in a digital temperature water bath at $37^{\circ} \mathrm{C}$. SBF and blood plasma ion concentrations are given in Table I. A weight / volume solution ratio equal to $0.002 \mathrm{~g} / \mathrm{cm}^{3}$ was used for all samples tested. SBF immersion tests were made in triplicate. Chemically non-treated samples were removed from the SBF solution after 5 days, while the treated ones were removed after 5 and 10 days. All the samples were carefully rinsed twice with distilled water and dried at room temperature after removal from the SBF solution. The rinsing procedure was important to eliminate some aqueous soluble salts, such as $\mathrm{NaCl}$, deposited onto the fiber surfaces. For all experiments, the SBF solution was completely removed and replaced every $48 \mathrm{~h}$ by a fresh solution to avoid contamination by microorganisms and to keep the $\mathrm{pH}$ close to 7.3.

\subsection{Characterization methods}

The morphology of the fibers was studied using Scanning Electron Microscopy (SEM) (JEOL-JSM 840 A). Prior to analysis, the samples were fastened to a sample holder with the help of a double carbon ribbon and covered with gold. Energy Dispersive Spectroscopy (EDS) (JEOL-JXA 8900RL) was also used to evaluate semi-qualitatively the composition of the fibers. Sample structure and homogeneity, and HA layer formation were characterized by comparison of FTIR spectra (Bomen MB-100C23 FTIR) of different samples. For these analyses, samples were pressed against a diamond sample holder and analyzed in transmission mode. The determination of $\zeta$ potential was performed in COULTER DELSA 440SX. For this, a suspension of ground material in deionized water was homogenized with ultrasound for $15 \mathrm{~min}$. Afterwards, another suspension was made by adding drops of the previous suspension into an aqueous solution of $\mathrm{KCl} 10^{-3} \mathrm{M}$. The $\mathrm{pH}$ of the initial solution was measured and adjusted to the range from 2 to 12 with an aqueous solution of either $\mathrm{KOH} 10^{-3} \mathrm{M}$ or $\mathrm{HNO}_{3} 10^{-3} \mathrm{M}$.

\section{Results and discussion}

SEM micrographs of TEOS-treated and non-treated fibers did not show significant morphological differences. However, EDS spectra (Fig. 1) showed that the TEOS treatment was effective in producing a silica layer on the fiber surface. A Si peak appears, while in those pure collagen it is absent, indicating that this surface was recovered by $\mathrm{Si}$.

Non-treated fibers did not evidence any adherent coating after 5-day SBF immersion. More extended periods were not investigated, because there is a faster fiber degradation after 5 days. Otherwise, treated samples presented a coating after 5 days in SBF, which remained even after water rinsing. This coating was reasonably continuous after 10 days (Fig. 2), and the morphology of the layer was consistent

Table 1. Ionic concentration (mM) of human plasma and of Simulated Body Fluid (SBF).

\begin{tabular}{lcccccccc}
\hline & $\mathrm{Na}^{+}$ & $\mathrm{K}^{+}$ & $\mathrm{Ca}^{2+}$ & $\mathrm{Mg}^{2+}$ & $\mathrm{Cl}^{-}$ & $\mathrm{HCO}_{3}^{-}$ & $\mathrm{HPO}_{4}^{2-}$ & $\mathrm{SO}_{4}^{2-}$ \\
\hline SBF & 142.0 & 5.0 & 2.5 & 1.5 & 147.8 & 4.2 & 1.0 & 0.5 \\
Human Plasma & 142.0 & 5.0 & 2.5 & 1.5 & 103.0 & 27.0 & 1.0 & 0.5 \\
\hline
\end{tabular}

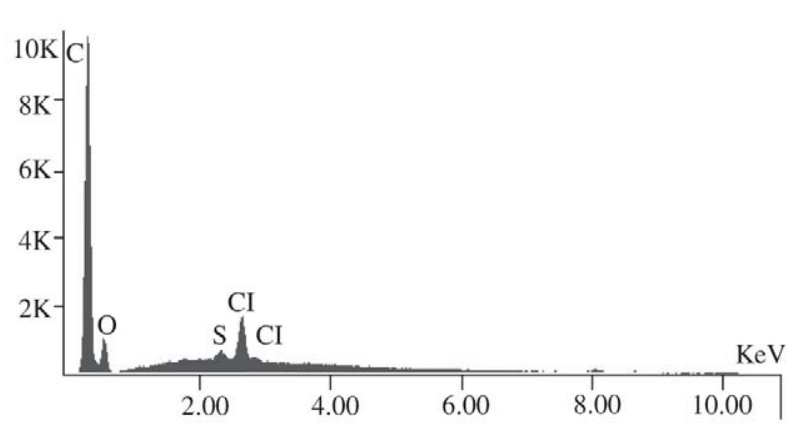

(a)

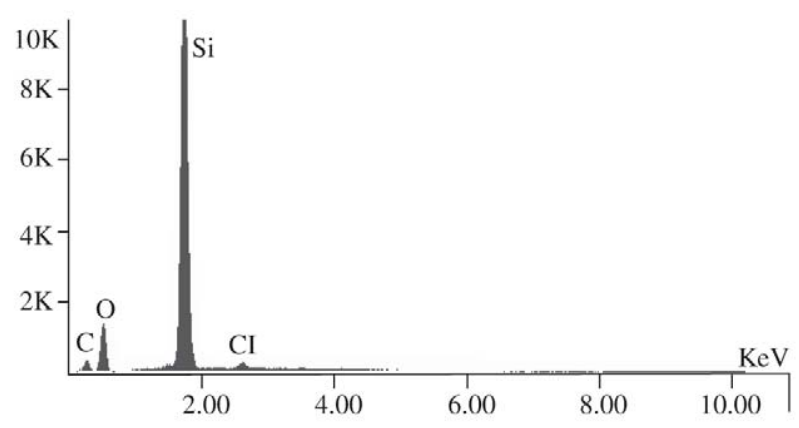

(b)

Figure 1. EDS of collagen fibers: a) from control group, b) chemically treated with TEOS for $1 \mathrm{~h}$. 
with the different immersion times. EDS analysis (Fig. 3) shows the presence of $\mathrm{Ca}$ and $\mathrm{P}$ in this coating not seen before immersion in SBF.

FTIR spectra of the different samples before and after SBF immersion for 5 days are shown in Fig. 4. Collagen (Fig. 4a), exhibits typical bands such as $\mathrm{C}=\mathrm{O}$ stretching at $1653 \mathrm{~cm}^{-1}$ for amide I, N-H deformation at $1545 \mathrm{~cm}^{-1}$ for amide II and N-H deformation at 1233 and $1281 \mathrm{~cm}^{-1}$ for amide III band ${ }^{14-16}$. The sample bands are observed in the Fig. 4c.

After TEOS treatment (Fig. 4b), absorption bands at 1170, 1080, 800 and $460 \mathrm{~cm}^{-1}$ due to the Si-O-Si bonds

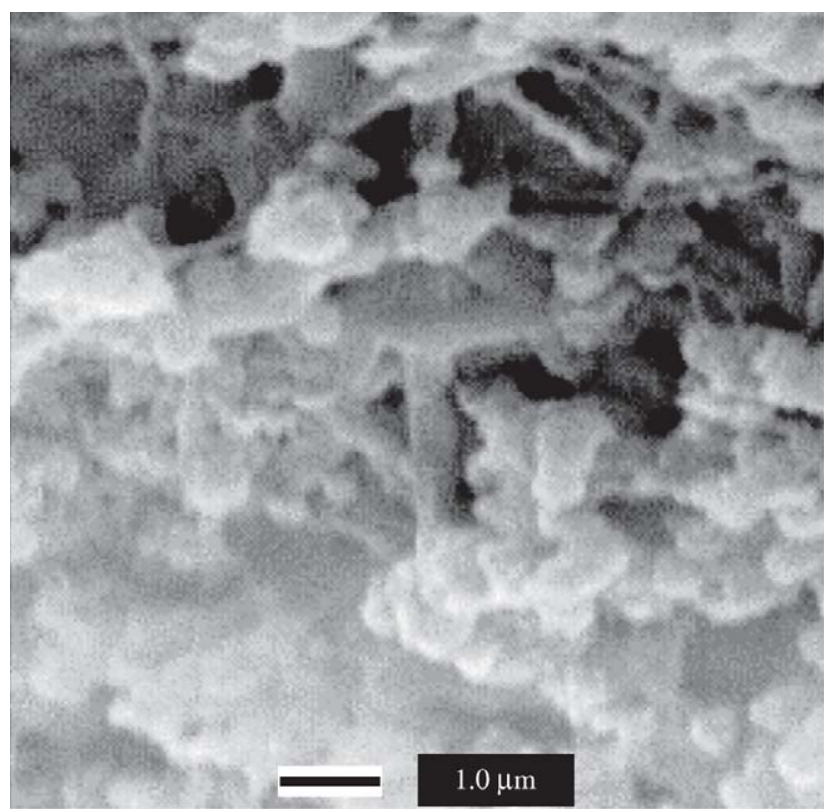

Figure 2. Collagen sample chemically treated with TEOS for $1 \mathrm{~h}$ and immersed in SBF solution for 10 days.

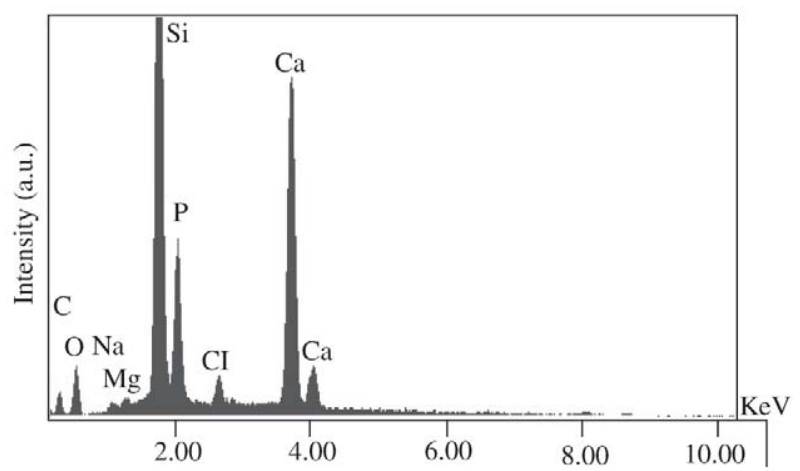

Figure 3. EDS for sample chemically treated with TEOS for $1 \mathrm{~h}$ and immersed for 10 days in SBF solution. appeared ${ }^{17,18}$ together with peaks at 960 and $550 \mathrm{~cm}^{-1}$ associated to $\mathrm{OH}$ and $\mathrm{Si}-\mathrm{OH}$ bands, respectively ${ }^{19}$ (Fig. $4 \mathrm{~b}$ ). The spectrum for treated samples immerged in SBF for 5 days (Fig. 4d) presented other peaks at $1060 \mathrm{~cm}^{-1}, 598 \mathrm{~cm}^{-1} \mathrm{re}-$ ferring to $\mathrm{P}-\mathrm{O}$ bonds (P-O asymmetric stretch), and 940 $\mathrm{cm}^{-1}, 603 \mathrm{~cm}^{-1}$, and $560 \mathrm{~cm}^{-1}$ (P-O bending modes) ${ }^{17}$ characteristic of $\mathrm{HA}$, beside bands related to the $\mathrm{Si}-\mathrm{O}-\mathrm{Si}$ bond at $810 \mathrm{~cm}^{-1}$ and $460 \mathrm{~cm}^{-1}$. Longer immersion times enhanced absorbance at $603 \mathrm{~cm}^{-1}$, and consequently this peak becomes more clearly defined.

Fig. 5 shows $\zeta$ potential variations as a function of solution $\mathrm{pH}$ for: collagen, chemically treated sample, and pure

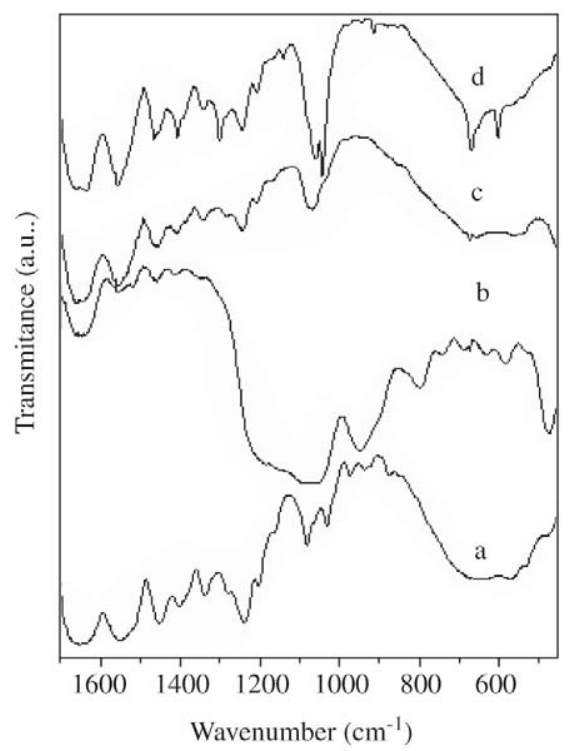

Figure 4. FTIR spectra of collagen samples: a) before any chemical treatment, b) after TEOS treatment, c) immersed for 5 days in SBF solution, d) chemically treated and immersed in SBF solution for 5 dave

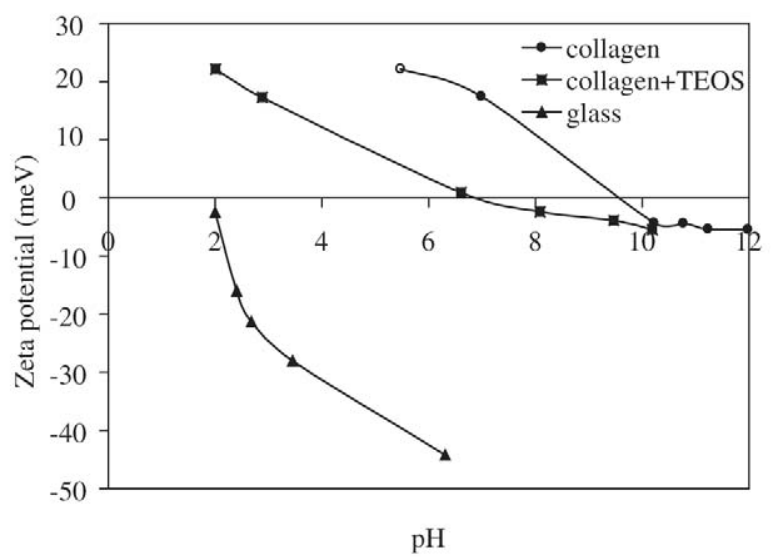

Figure 5. Zeta potencial $(\xi)$ of collagen, TEOS-treated collagen, and glass. 
silica glass. The $\mathrm{pH}$ corresponding to the isoelectric point $\left(\mathrm{pH}_{\mathrm{IEP}}\right)$ of collagen is about 10 . Chemically treated samples exhibited a $\mathrm{pH}_{\mathrm{IEP}}$ of 6.8 , evidencing the partial covering of the collagen surface by silica. As expected, glass $\mathrm{pH}_{\text {IEP }}$ was 2 , similar to silica $\mathrm{pH}_{\text {IEP }}{ }^{20}$. This shift from 10 to 6.8 was sufficient to charge the material surface negatively when in contact with the SBF solution. This explains why treated fibers show a bioactive behavior, while not-treated ones do not.

\section{Conclusions}

TEOS treatment applied to collagen fibers resulted in a silica coating that decreased $\mathrm{pH}_{\mathrm{IEP}}$, from 10 , for pure collagen, to 6.8. This shift was sufficient to charge the material negatively when in contact with the SBF solution. This result can explain why treated collagen shows a bioactive behavior, while non-treated collagen does not. Moreover, TEOS treatment enhances fiber degradation time in physiological solution.

\section{Acknowledgments}

One of the authors (ALA) acknowledges support of Brazilian Government - Conselho Nacional de Desenvolvimento Científico e Tecnológico (CNPq).

\section{References}

1. Hench, L.L. Advances in Ceramics Processing, In: Bincenzini P, ed.. Imola, Faenza, p. 92-100, 1978.

2. Hulbert, S.F.; Hench, L.L.; Forbers, D.; Bowman, L.S. Ceramics Int, v. 8, p.131- 140, 1982.

3. Haman, J.D.; Scripa, R.N.; Rigsbee, J.M.; Lucas, L.C. Journal of Materials Science: Materials in Medicine, v. 13, n. 2, p. 175-184, 2002.

4. Mucalo, M.R.; Yokogawa, Y.; Suzuki, T.; Kawamoto, Y.; Nagata, F., Nishizawa, K. Journal of Materials Science: Materials in Medicine, v. 6, n. 11, p. 658-669, 1995.
5. Kokubo, T.; Kushitani, H.; Sakka, S.; Kitsugi, T.; Yamamuro, T. Journal of Biomedical Materials Research, v. 24, n. 6, p. 721-734, 1990.

6. Kokubo, T. Journal of Non-Crystalline Solids, v. 120, n. 1-3, p. 138-151, 1990.

7. Andersson, O.H.; Karlsson, K.H. Journal of Non-Crystalline Solids, v. 129, n. 1-3, p. 145-151, 1991.

8. Kokubo, T.; Kushitani, H.; Ohtsuki, C.; Sakka, S.; Yamamuro, T. Journal of Materials Science: Materials in Medicine, v. 3, n. 2, p. 79-83, 1992.

9. Kasuga, T.; Nakagawa, K.; Yoshida, M.; Miyade, E. Journal of Materials Science, v. 22, n. 10, p. 3721-3724, 1987.

10. Hench, L.L.; Splinter, R.J. Journal Biomedical Material Research, v. 36, p. 117-141, 1971.

11. Hench, L.L. Journal of the American Ceramic Society, v. 74, n. 7, p. 1487-1510, 1991.

12. Hwang, K.S.; Song, J.E.; Jo, J.W.; Yang, H.S.; Park, Y.J.; Ong, J.L.; Rawls, H.R. Journal of Materials Science: Materials in Medicine, v. 13, n. 1, p. 133-138, 2002.

13. Rhee, S.H.; Lee, J.D.; Tanaka, J. Journal of the American Ceramic Society, v. 83, n. 11, p. 2890-2892, 2000.

14. Payne, K.J.; Veis, A. Biopolymers, v. 27, n. 11, p. 17491760, 1988.

15. Doyle, B.B.; Bendit E.G.; Blout, E.R. Biopolymers, v. 14, n. 5, p. 937-957, 1975.

16. Paschalis, E.P.; Betts, F.; DiCarlo, E.; Mendelsohn, R.; Boskey, A.L. Calcified Tissue International, v. 61, n. 6, p. 480-486, 1997.

17. Bertoluzza, A.; Fagnano, C.; Morelli, M.A.; Gottardi, V.; Guglielmi, M. Journal of Non-Crystalline Solids, v. 48, n. 1, p.117-128, 1982.

18. Matos, M.C.; Ilharco, L.M.; Almeida, R.M. Journal of Non-Crystalline Solids, v. 147, p. 232-237, 1992.

19. Yoshino, H.; Kamiya, K.; Nasu, J.Non-Crystalline Solids, v. 126, n. 1-2, p. 68-78, 1990.

20. Parks, G.A. Chem Rev., v. 65, n. 2, p. 177-198, 1965. 